\title{
Extraction of chitin from chitosan from exoskeleton of shrimp for application in the pharmaceutical industry
}

\author{
*Yateendra Shanmukha Puvvada', Saikishore Vankayalapati², Sudheshnababu Sukhavasi ${ }^{3}$ \\ ${ }^{1}$ Bapatla College of Pharmacy, Bapatla, Andhra Pradesh, India \\ ${ }^{2}$ Associate Professor, Bapatla College of Pharmacy, Bapatla, Andhra Pradesh, India \\ ${ }^{3}$ Bapatla College of Pharmacy, Bapatla, Andhra Pradesh, India
}

\begin{abstract}
Chitosan is an amino polysaccharide prepared by processing shrimp waste (shell) which involves partial deacetylation of chitin. Chitosan, a versatile natural polysaccharide, the second most abundant natural polymer. Many biochemists have found that chitosan as biocompatible, biodegradable and non toxic which made wide applicability in conventional pharmaceutics as a potential formulation excipient. In this research mainly the focused on the synthesis of chitosan which is suitable for the pharmaceutical industry especially in the designing delayed and controlled drug delivery systems. The main study focused on preparation low molecular weight of the chitosan suitable for pharmaceutical industry. The crude chitin was collected from exoskeleton of Triopslongicaudatus and Triopscancriformis specimens which are then processed to obtain chitosan. The chitosan yield was found to be $35.49 \%$ and it was analyzed for its physiochemical parameters.
\end{abstract}

Key Words: Chitin, extraction, purification, characterisation, pharmaceutical grade chitosan.

\section{INTRODUCTION}

Chitosan, a natural polysaccharide, is being widely used as a pharmaceutical excipients (Singla Struszczyk, 2002). It is obtained by the partial deacetylation of chitin, natural polymer composed of randomly distributed $\beta-(1-4)$-linked Dglucosamine.It consists of two types of monomers; chitin-monomers and chitosanmonomers. Chitin is a linear polysaccharide consisting of (1-4)-linked 2acetamido-2-deoxy-b-D-glucopyranose. Chitosan is alinear polysaccharide consisting of (1-4)-linked 2amino-2-deoxy-b-D-glucopyranose (Tomihata and Ikada, 1997; Roberts, 1992).

The amino group in chitosan has a pKa value of $\sim 6.5$, thus, chitosan is positively charged and soluble in acidic to neutral solution with a charge density dependent on $\mathrm{pH}$ and the percentage of degree of

\footnotetext{
*Corresponding Author:

Yateendra Shanmukha Puvvada

Bapatla College of Pharmacy

HNO 53 Vivekananda Colonny

Ii Lane, Suryalanka Road, Bapatla 522101, India.

E-mail:pr.shanmukhapuvvada@gmail.com

Contact No.: +919963395220
}

deacetylation- value. In other words, chitosan is bioadhesive and readily binds to negatively charged surfaces such as mucosal membranes. Chitosan enhance the transport of polar drugs across epithelial surfaces, and is biocompatible and biodegradable. Purified qualities of chitosans are available for biomedical application (Cho et al., 1998).

Chitosan insipite of its unique properties is proving its efficacy in various dosage forms such as bioadhesive nature, hydrophilic macromolecule drug carrier, effective carrier in drug targgetting to brain, transdermal films and wound healing biodegradable grafts, hyperlipidemic , antimicrobial and stabilizing constituent of liposomes. Chitosan for its pontential makes it as a promising candidate as pharmaceutical excipient (Muzzrelli et al., 1996; Lehr et al., 1992).

The presence of a number of amino groups permit chitosan to chemically react with anionic systems, thereby resulting in alteration of physicochemical characteristics of such combinationssome of which include binding, disintegrating and tablet coating 
properties (Frizakepsutlu et al., 1999). The polymer in another form i.e available as d-glucosamine commercially with the slightest chemical modification has also been investigated as a potential treatment for arthritis. Chitosan alone is biologically active which is efficient in managing dietary treatments and also exhibit pharmacology as antimicrobial, hypocholesterolemic and would healing. Its unique structure makes opens its applicability as promising candidate not only as pharmaceutical aid but also in specific drug targeting and delivery. This research mainly focuses on the synthesisof pharmaceutical grade chitosan confining to predetermined quality attributes of its physiochemical properties such as gram molecular weight, viscosity, the extent of deacetylaltion, reminisces after burnt, water log content, present of heavymetals etc.

\section{MATERIALS AND METHODS}

\section{Sample preparation}

The shrimps were obtained from Penaeuscarinatus and Penaeusmonodon specimens collected from Suryalanka coast (Lat.15.83454 ${ }^{\circ} \mathrm{NLong} .80 .50507^{\circ} \mathrm{E}$ ) and the shell and operculum are removed from the animal. The shrimps exoskeletons collected are placed in Ziploc bags and refrigerated overnight Approximately1500 grams of crushed shrimp's exoskeletons wet samples were placed on foil paper and measured using a balance. The shrimp exoskeletons were crushed into smaller pieces using a meat tenderizer. The samples were oven-dried for 4 consecutive days at $65^{\circ} \mathrm{C}$ until constant weight. The dry weights of the samples were determined to be 1269 grams. The obtained shrimp is made into 4 equal parts for efficient material handling (Toan, 2009).

\section{Extraction of chitin and chitosan}

The chitin and chitosan sequence involves washing of crushed exoskeletons. crushed shrimps exoskeletons were placed in $1000 \mathrm{ml}$ beakers and soaked in boiling sodium hydroxide ( 2 and $4 \% \mathrm{w} / \mathrm{v}$ ) for one hour in order to dissolve the proteins and sugars thus isolating the crude chitin. $4 \% \mathrm{NaOH}$ is used for chitin preparation, concentration used by the scientists at the Sonat Corporation (Lertsutthiwong et al., 2002). After the samples are boiled in the sodium hydroxide, the beakers containing the shrimp shell samples are removed from the hot plate, and allowed to cool for 30 minutes at room temperature (Lamarque et al.,2005). The exoskeletons are then further crushed to pieces of $0.5-5.0 \mathrm{~mm}$ using a meat tenderizer.

\section{Demineralization}

The grounded exoskeleton is demineralizedusing $1 \% \mathrm{HCl}$ with four times its quantity. The samples were allowed to soak for $24 \mathrm{~h}$ to remove the minerals (mainly calcium carbonate) (Trung et al., 2006). The demineralized shrimp shell samples were then treated for one hour with $50 \mathrm{ml}$ of a $2 \% \mathrm{NaOH}$ solution to decompose the albumen into water soluble amino-acids. The remaining chitin is washed with deionized water, which is then drained off. The chitin was further converted into chitosan by the process of deacetylation (Huang et al., 2004).

\section{Deacetylation}

The deacetylation process is carried out by adding $50 \% \mathrm{NaOH}$ and then boiled at $100^{\circ} \mathrm{C}$ for $2 \mathrm{~h}$ on a hot plate. The samples are then placed under the hood and cooled for $30 \mathrm{~min}$ at room temperature. Afterwards the samples are washed continuously with the $50 \% \mathrm{NaOH}$ and filtered in order to retain the solid matter, which is the chitosan. The samples were then left uncovered and oven dried at $110^{\circ} \mathrm{C}$ for $6 \mathrm{~h}$. The chitosan obtained will be in a creamywhite form (Muzzarelli and Rochetti, 1985).

\section{Purification of Chitosan}

The obtained chitosan has to be purified to make it suitable for the pharmaceutical use. The purification process was designed in three steps

1) Removal of insolubles with filteration

2) Reprecipitation of chitiosan with $1 \mathrm{~N} \mathrm{NaOH}$

3) Demetallisation of retrieved chitosan

\section{Removal of insolubles with filtration}

$1 \mathrm{mg} / \mathrm{ml}$ chitosan acetic acid $1 \%(\mathrm{v} / \mathrm{v})$ solution is prepared by a magnetic stirrer until an homogenous solution is obtained. The insolubles were removed by filteration through Whatman filter paper $22 \mu \mathrm{m}$.

\section{Reprecipitation of chitosan with $1 \mathrm{~N} \mathrm{NaOH}$}

Chitosan was precipitated from filtered chitosan solution by titration with $1 \mathrm{~N} \mathrm{NaOH}$ until $\mathrm{pH}$ value of 8.5. The chitosan obtained is washed several times with distilled water by centrifuging at 8,000 to 
$10,000 \mathrm{xg}$. All the above steps were carriedin the presence of reducing agent Dithiothreitol, (DTT) in order to provide more consistency and reproducibility between chitosan batches for biomedical applications (any other hydroxides other than $\mathrm{NaOH}$ are reactive which would another step in purification if such materials are used).

\section{Demetallisation of retrieved chitosan}

Reprecipitation precedes demetallisation by the addition of $1 \mathrm{ml}$ of $10 \% \mathrm{w} / \mathrm{v}$ Aqueous solution of sodium dodecyl sulfate (SDS) and stirring for 30 min for dissolving the protein left over finally. After leaving the solution stirring at room temperature overnight, $3.3 \mathrm{ml}$ of $5 \% \mathrm{w} / \mathrm{v}$ ethylenediaminetetraacetic acid (EDTA) was added and stirred at room temperature for 2 additional hours for precipitation of heavy metals with EDTA. The water insoluble chitosan precipitate was collected by centrifugation at 5000xg for30 min using REMI and washed several times with distilled water by resuspending and recentrifugation for $30 \mathrm{~min}$. the residue obtained is dried in hot air oven at 60 gently to prevent physical damage in the chain structure. The obtained dried chitosan is stored in the dessicator (Qian and Glanville, 2005).

\section{Characterization of prepared chitosan Molecular weight}

Average molecular weight of chitosan is determined by determination of its Intrinsic viscositybu Brookfield viscometer. $1 \mathrm{mg} / \mathrm{ml}(\mathrm{w} / \mathrm{v})$ concentration of chitosan solution was prepared using $1 \%$ glacial acetic acid by a magnet stirrer for homogenous mixture of the polymer solution. The viscosity of the chitosan solution was analysed using spindle RV-VI. The average molecular weight was obtained from Mark-Houwink equation:

$\eta=K M^{a}$

Where $[\eta]$ is the intrinsic viscosity, $M$ is average molecular weight of the solution respectively and $\mathrm{K}$ and a are the Mark-Houwink constants specific for a given polymer (Merlina A et al., 2009).

\section{Viscosity}

Viscosity of chitosan solutions will be determined at room temperature by using a Brookfield digital viscometer (Mirzadehl et al., 2002).

\section{Degree of deacetylation}

Degree of deacetylation refers to the removal of acetyl group from the chain this is determined by potentiometric titration. Chitosan homogenous solution is prepared using dil. $\mathrm{HCl}$ containing 0.010 $\mathrm{mol} / \mathrm{L}$ which is titrated against $0.1 \mathrm{M} \mathrm{NaOH}$. The end point is detected by the inflections of the $\mathrm{p}^{\mathrm{H}}$ values. Two inflections were mainly noted out of which first one corresponds to neutralization of $\mathrm{HCl}$ and second one to the neutralization of ammonium ions for chitosan chain. The difference between two points give the amount of the amino groups in the chitosan chain ( degree of deacetylation) (Zhanga et al., 2011).

$D D \%=100-\mathrm{DA} \%$

\section{$p H$}

The $\mathrm{pH}$ measurements of the chitosan solutions will be carried out using a microprocessor $\mathrm{pH}$ meter.

\section{Ash value}

To determine the ash value of chitosan, $2.0 \mathrm{~g}$ of chitosan sample is placed into previously ignited, cooled, and tarred crucible. The samples are heated in a muffle furnace preheated to $650^{\circ} \mathrm{C}$ for $4 \mathrm{hr}$. The crucibles are allowed to cool in the furnace to less than $200^{\circ} \mathrm{C}$ and then placed into desiccators with a vented top. Percentage of ash value is calculated using the following. (MonarulIslama Shah et al., 2011).

$\%$ Ash $=\frac{(\text { weight of residue, } g)}{\text { sample weight, } g} \times 100$

\section{Loss on drying}

Loss on drying of the prepared chitosan will be determined by the gravimetric method. The water mass loss will be determined by drying the sample to constant weight and measuring the sample after and before drying. The water mass (or weight) will be the difference between the weights of the wet and oven dry samples. (Yong Hu et al., 2002).

$\%$ loss on drying $=\frac{(\text { Wet weight }- \text { Dryweight })}{\text { Dryweight }} \times 100$

\section{FTIR studies of chitosan}

The FT-IR spectrum of the standard chitosan showed nine major peaks at the ranges of 752,893 , 1022, 1421, 1552, 1643, 2865, 2921 and $3283 \mathrm{~cm}^{-1}$; whereas the chitosan sample from penaeusmonodon. 
Table 1: Characteristics of chitosan obtained from the panaeusmonodon.

\begin{tabular}{ll}
\hline Characteristics & Chitosan \\
\hline Chitosan yield & $34 \%$ \\
Average molecular weight & $1,599,558.029$ \\
Degree of deacetylation & $89.79 \%$ \\
Viscosity & $304 \mathrm{cps}$ \\
$\mathrm{pH}$ & 8.5 \\
Ash value & $0.25 \%$ \\
Loss on drying & $9.34 \%$ \\
Heavy metals & $>10 \mathrm{ppm}$ \\
\hline
\end{tabular}

\section{RESULTS AND DISCUSSION}

The synthesis of chitosan involves various chemical steps such as preparation of the chitin from the crude shells which will be the initiation of thechitosan synthesis with the removal of the proteins in the shells followed by demineralization for the removal of the carbon and other salts present in the crude form which will be preceded by the deacetylation of the chitin that would result in chitosan. The regular chitosan is obtained by following the above steps, but a polymer of pharmaceutical grade has to fall in the region of its predetermined quality aspects and Usually commercial chitins are prepared by a first step of deproteinisation followed by a second step of demineralization. The whole parameters were tabulated in the table1 and their respective characteristics are discussed. The chitosan yield was found to be $34 \%$ after purification of the total exoskeleton taken. In these conditions the native structure of the chitin is lost, is extracted. On the otherhand, "in which the native chain and fibrous structures are intact and stabilized, is extracted when demineralization occurred in the first step.

Early studies have clearly demonstrated that specific characteristics of these products (Mw, DD) depend on the process conditions. Taking these two facts into account, the reaction conditions must be controlled when preparing chitosan. The chitosan obtained from the above process was reported to have average molecular weight of 1,599,558.029 which literally conclude that majority of the linkage was intact instead of splitting up by the influence of the strong alkali. The purification procedure included removing insoluble contaminations and adding deproteinization and demetallization agents, SDS and EDTA, respectively, in the presence of the
Table 2: Wave length of the main bands obtained for the standard chitosan and chitosan extracted from $\mathbf{N}$. crepidularia.

\begin{tabular}{lll}
\hline Vibration modes & Standard & $\begin{array}{l}\text { Penaeus- } \\
\text { monodon }\end{array}$ \\
\hline NH out - of - plane bending & 752 & 752 \\
Ring stretching & 896 & 893 \\
$\mathrm{CO}$ stretching & 1026 & 1022 \\
$\mathrm{CH}_{2}$ bending and $\mathrm{CH}_{3}$ deformation & 1418 & 1421 \\
Amide II band & 1563 & 1552 \\
Amide I band & 1661 & 1643 \\
$\mathrm{CH}$ stretching & 2878 & 2865 \\
Symmetric $\mathrm{CH}_{3}$ stretching and & 2930 & 2921 \\
asymmetric $\mathrm{CH}_{2}$ stretching & & \\
NH stretching & 3268 & 3283 \\
\hline
\end{tabular}

reducing agent, DTT. This resulted in the formation of water insoluble chitosan precipitates or flocculants, and water soluble supernatants that included the deproteinization agent and any proteins that havecomplexed with it and the demetallization agent with the extracted metals. Adding the reducing agent enhanced the water solubilization of protein impurities by dissociating any disulfide bonds present in the proteins. The demetallization agent was mixed with the chitosan solutions under basic $\mathrm{pH}$ conditions to avoid the formation of chitosan-metalchelate conjugates. The degree of deacetylation (DD) of chitosan plays a significant role for determining the specific applications of chitosan.

Degree of deacetylation of the compound is $89.79 \%$ However, these higher DD values are the consequence of the high amount of protein, yielding high quality of chitosan suitable for the pharmaceutical application. Degree of deacetylation affects thechemical, physical and biological properties of chitosan, such as adsorption, covalent linking, encapsulation. The viscosity of the pharmaceutical chitosan is very important aspect in handling as polymer for the drug delivery. The viscosity profile $304 \mathrm{cps}$ of the chitosan prepared shows that it would fall under the region of most pharmaceutical products do which are suitable for designing drug delivery systems..The Prolonged decalcification time, even during $24 \mathrm{~h}$, results in a very slight drop in the ash content but can cause polymer degradationthe calicium carbonate which demonstrates as ash value is very low. The FT-IR studies of the chitosan from standard commercial species. The 


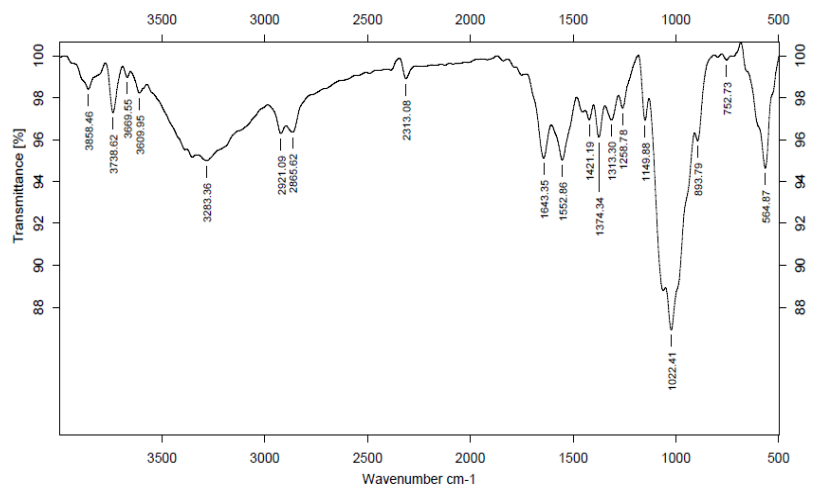

Figure 1: The FT-IR report of the standard chitosan.

major absorption band is observed between 1220 and $1020 \mathrm{~cm}^{-1}$ which represents the free amino group $\left(-\mathrm{NH}_{2}\right)$ at $\mathrm{C} 2$ position of glucosamine, a major group present in chitosan. Further the sample showed the absorption bands for the free amino group between 1026 and $1259 \mathrm{~cm}^{-1}$ when the peak at $1374 \mathrm{~cm}^{-1}$ represents the $-\mathrm{C}-\mathrm{O}$ stretching of primary alcoholic group $\left(-\mathrm{CH}_{2}-\mathrm{OH}\right)$. The absorbance bands of $3268,2930,2878,1563$, and $1418 \mathrm{~cm}^{-1}$ indicated the $\mathrm{N}-\mathrm{H}$ stretching, Symmetric $\mathrm{CH}_{3}$ stretching and asymmetric $\mathrm{CH}_{2}$ stretching, $\mathrm{CH}$ stretching, $\mathrm{C}=\mathrm{O}$ stretching in secondary amide (amide I) and C-Nstretching in secondary amide (amide II), respectively. In the present study also the same absorbance bands were observed at 3283, 2921, 2865,1643,1552,1421, 1022, 893and $752 \mathrm{~cm}^{-1}$ which confirms the structure of chitosan from table 2 and figure 1 and 2.

\section{CONCLUSION}

Pharmaceutical industry is in need of different types of chitosan presently available in the market which are to be refined further more to meet the required standards. For instance Chitosan used in the wound healing and scaffolds must be in the form of oligomeres having low molecular weight in former case where as later ones need more proliferated structure and high molecular weight for tissue engineering. Drug delivery systems such as floating, intestinal, and other gel forms require high molecular weight with high degree of deacetylation. Simultaneously vaccine, gene, and enzyme drug delivery systems are suitable in high molecular weight chitosans which are highly deacetylated $(>85 \%)$, different techniques are employed for these

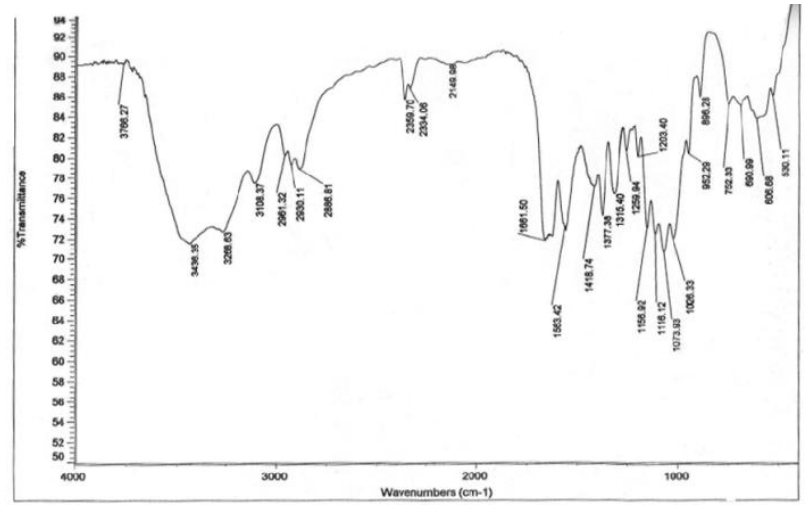

Figure 2: The FT-IR report of the chitosan extracted from the penaeusmonodon.

type of drug delivery systems such as adsorption, covalent linking, encapsulation, which require dense network, potentially charged ends and long chains respectively. Chitosan is used in design of many different types of drug carriers for various administration routes like oral, parenteral, nasal, buccal, transdermal, vaginal, topical etc. It can be formulated as nanoparticles, microspheres, membrane sponge etc. For drug delivery, special preparation techniques are used to prepare chitosan drug carriers by taking care such parameters as cross linker concentration, chitosan molecules weight and processing conditions all these effect release rate of the loaded drug. Chitosan seems to be the biopolymer for the development of new derivatives such as Water-soluble derivatives of chitosan , Quaternarized derivatives, Caboxyalkylation, Chitosan Esters, sulfonated derivatives of chitosan, N-trimethylene chloride chitosan, Chitosan conjugates:

\section{ACKNOWLEDGEMENT}

The authors would like to express thanks to the Mr. Everest Edward, Managing Director of India Sea Food, Chochin, Kerala for his generous support and valuable advices in carrying this research work.

\section{REFERENCES}

Cho, Y., No, H.K., and Meyers, S.P., (1998). Physicochemical characteristics' and functional properties of various commercial chitin and chitosan products. Journal of Agriculture and Food Chemistry, 46(9), 3839-3843. [DOI]

Frizakepsutlu, ayhansavaser, yalcinozkan, necatidikmen and askinisimer. (1999) Evaluation of chitosan used as excie- 
pient in tablet formulation. Acta poloniae pharmaceuticadrug research, 56(3):227-235.

Huang, M. et al. (2004) Uptake and cytotoxicity of chitosan molecules and nanoparticles: Effects of molecular weight and degree of deacetylation. Pharmaceutical Research, 21 (2), 344-353. [DOI]

Lamarque, G. et al. (2005) Physicochemical behavior of homogeneous series of acetylated chitosans in aqueous solution: role of various structural parameters. Biomacromolecules, 6 (1), 131-142. [DOI]

Lehr CM, Bouwstra JA, Schacht EH, Junginger HE. (1992) Formulation and evaluation of mucoadhesiveglipizidemicrospheresInt. J. Pharm, 78, 43-48. [DOI]

Lertsutthiwong, P., How, N.C., Chandrkrachan, S. and Stevens, W.F. (2002) Effect of chemical treatment on the characteristics of shrimp chitosan. Journal of metals, materials and minerals, 12(1): 11-18.

Merlinaa ,delorino and salvacion p . (2009) cresidio Investigation of chitosan from squid pen as Scar Remover. World applied sciences journal 5 (special issue for environment) 98-103.

Mirzadeh, H., Yaghobi., N., Amanpour, S., Ahmadi, H., Mohagheghi, M.A. and Hormozi, F. (2002) Preparation of Chitosan Derived from Shrimp's Shell of Persian Gulf as a Blood Hemostasis Agent. Iranian Polymer Journal, 11(1): 63-68.

MonarulIslama Shah., Md. Masumb., M. MahbuburRahmana., Md. Ashraful Islam Mollab. (2011) Preparation of Chitosan from Shrimp Shell and Investigationof Its Properties. International Journal of Basic \& Applied Sciences IJBAS-IJENS, 11(1), 116-130.

Muzzarelli RAA, Rochetti R. (1985) Determination of the degree of deacetylation of chitosan by first derivative ultraviolet spectrophotometry. J CarbohydrPolym, 5, 46172. [DOI]
Muzzrelli, R.A.A., Terbojevich, M. and Cosani, A. (1996) Unspecific activities of lipases and amylases on chitosans. In: Chitin Enzymology Vol. 2, R.A.A.Muzzarelli (ed), Atec, Grottammare, Italy, 69-82.

Qian, R.Q. and Glanville, R.W. (2005) Methods for purifying chitosan Providence Health System.

Roberts GAF (1992). Preparation of chitin and chitosan. The Macmillan UK: London Press.

SinglaStruszczyk, M.H. (2002) Chitin and chitosan - Part II. Applications of chitosan. Polimery, 47 (6), 396-403

Toan, N.V. (2009) Production of Chitin and Chitosan from Partially Autolyzed Shrimp Shell Materials. The Open Biomaterials Journal, 1:21-24. [DOI]

Tomihata, K. and Ikada, Y. (1997) In vitro and in vivo degradation of films of chitin and its deacetylated derivatives. Biomaterials, 18 (7), 567-575. [DOI]

Trung TS, Thein-Han WW, Qui NT, Ng CH, Stevens WF. (2006) Functional characteristics of shrimp chitosan and its membranes as affected by the degree of deacetylation. BioresourTechnol, 97(4), 659-63. [DOI]

Yong Hu.,Xiqun Jiang., Yin Ding., Haixiong Ge., Yuyan Yuan.,Changzheng Yang . (2002) Synthesis and characterization of chitosan-poly(acrylic acid) nanoparticles. Elsevier Science Ltd. Biomaterials, 23, 3193-3201. [DOI]

Zhanga Y., Zhanga, X., Dinga, R., Zhanga, J. \&Liub, J. (2011) Determination of the degree of deacetylation of chitosan by potentiometric titration preceded by enzymatic pretreatment. Carbohydrate Polymers, Vol. 83, 813-817. 